\title{
Consumo de forragem e produção de leite de vacas em pastagem de azevém-anual com duas ofertas de forragem ${ }^{1}$
}

\author{
Henrique Mendonça Nunes Ribeiro Filho², Maicon Saulo Heydt² ${ }^{2}$ Elena Apezteguia Setelich \\ Baade $^{2}$, André Thaler Neto ${ }^{2}$
}

\footnotetext{
${ }^{1}$ Projeto parcialmente financiado pela Fundação de Apoio à Pesquisa Científica e Tecnológica do Estado de Santa Catarina (FAPESC).

2 Universidade do Estado de Santa Catarina. Avenida Luiz de Camões, 2090 CEP: 88520-000, Lages, SC.
}

\begin{abstract}
RESUMO - Avaliou-se o efeito de duas ofertas de forragem (25 e $40 \mathrm{~kg}$ MS/vaca.dia) sobre o consumo de forragem e a produção de leite em vacas pastejando azevém-anual. Utilizou-se o método rotacionado, em delineamento experimental de dupla reversão, com três períodos de 12 dias e dez vacas da raça Holandesa no terço médio de lactação. O consumo de forragem foi estimado pela produção fecal e pela digestibilidade da forragem ingerida e a produção de leite foi medida diariamente. A biomassa e a altura do dossel antes do pastejo não diferiram entre as ofertas de forragem. A altura pós-pastejo foi maior na oferta de forragem de $40 \mathrm{~kg} \mathrm{MS} / \mathrm{vaca}$.dia, o que determinou desaparecimento de forragem equivalente a 49,0\% nessa oferta de forragem e a 69,0\% na oferta de $25 \mathrm{~kg}$ MS/vaca.dia. O consumo individual de matéria seca (MS) da forragem foi 11,9 e 16,6 kg/dia e a produção de leite, 18,4 e 21,1 kg/dia nas ofertas de 25 e $40 \mathrm{~kg}$ MS/vaca.dia, respectivamente. Vacas leiteiras em pastagem de azevém com alta oferta de forragem podem ingerir mais de 16,0 kg de MS e produzir mais de $20 \mathrm{~kg}$ de leite/dia. A produção de leite reduz aproximadamente $0,2 \mathrm{~kg}$ a cada $\mathrm{kg}$ de diminuição na MS de forragem oferecida.
\end{abstract}

Palavras-chave: Lolium multiflorum, óxido de cromo, pastejo rotacionado

\section{Herbage intake and milk yield of dairy cows grazing Italian ryegrass at two herbage allowances}

\begin{abstract}
The effect of two herbage allowances (25 and $40 \mathrm{~kg}$ dry matter/cow.day) were assessed on the herbage intake and milk yield of dairy cows grazing Italian ryegrass. A rotational grazing system was used, according to a Change Over procedure with three 12-day periods and ten Holstein cows in mid-lactation. Individual herbage intake was estimated from fecal output and the digestibility of the selected herbage and the milk yield was measured daily. Pre-grazing sward height and herbage mass at ground level did not differ between treatments. Post-grazing sward height was higher 40 kg dry matter/cow.day and the pasture disappearance rate from the initial sward was $49.0 \%$ and $69.0 \%$, respectively. The individual dry matter intake of the herbage was 11.9 and $16.6 \mathrm{~kg} \mathrm{~kg} /$ day and the milk yield was 18.4 and. $21.1 \mathrm{~kg} /$ day at the allowances 25 and $40 \mathrm{~kg}$ dry matter/cow.day, respectively. Dairy cows grazing Italian ryegrass pasture, with a high forage allowance, can eat more than $16.0 \mathrm{~kg} \mathrm{DM} /$ day and produce more than $20 \mathrm{~kg}$ milk/day. The milk yield decreased around $0.2 \mathrm{~kg}$ per $\mathrm{kg}$ of reduction in DM offer.
\end{abstract}

Key Words: chromium oxide, Lolium multiflorum, rotational grazing

\section{Introdução}

A sustentabilidade econômica e ambiental dos sistemas de produção animal passa pela valorização do uso de forragem pastejada e tem como consequências a diminuição dos custos com alimentação e a menor contaminação do solo e das águas.

No caso específico da produção de leite, o sucesso da produção animal baseado no uso de pastagens depende do uso de forragens de excelente valor nutritivo e que sejam manejadas com o objetivo de possibilitar elevada ingestão de nutrientes. Neste contexto, o azevém-anual (Lolium multiflorum Lam.) é de larga data uma das plantas forrageiras de inverno mais utilizadas na Região Sul do Brasil. O seu excelente valor nutritivo e seu potencial para produção animal já foram observados em bovinos em crescimento, em diferentes regiões fisiográficas e tipos de solo (Difante et al., 2006; Saibro \& Silva, 1999), em ovinos de diferentes categorias na Depressão Central do Rio Grande do Sul (Farinatti et al., 2006, Frescura et al., 2005) e quando cultivado em associação com aveia (Avena strigosa Schreb) (Aguinaga et al., 2006; de Freitas et al., 2005, 
Bandinelli et al., 2005). Em contrapartida, poucos trabalhos foram conduzidos utilizando-se vacas em lactação, sem suplementação com concentrado, visando quantificar o potencial desta espécie forrageira para melhoria da eficiência dos sistemas de produção de leite baseados em pastagens.

Sabe-se, contudo, que pastagens de clima temperado, com valor alimentar semelhante ao do azevém-anual, como por exemplo, o azevém-perene (Lolium perenne L.), permitem que vacas de elevado potencial individual produzam média diária de $22 \mathrm{~kg} / \mathrm{leite}$ ao longo de toda a estação de crescimento da pastagem (Delaby et al., 2001). Entretanto, é imprescindível considerar a dependência dessa resposta à oferta de forragem, que tem efeito positivo e curvilinear no consumo de matéria seca (Delagarde et al., 2001a) e na produção de leite (Peyraud et al., 1996).

Dessa forma, os objetivos neste trabalho foram avaliar o consumo de forragem e a produção de leite em pastagem de azevém-anual e o impacto da oferta de forragem sobre essas variáveis. Testou-se a hipótese de que o azevémanual permite níveis de consumo e de produção de leite equivalentes aos observados com outras espécies de clima temperado, desde que manejado com alta oferta.

\section{Material e Métodos}

O trabalho foi conduzido no período de 19 de agosto a 28 de outubro de 2005, em uma área de 3,4 hectares. O solo no local é do tipo Cambissolo Húmico Alumínico com textura franca. Para implantação da pastagem, foram realizadas aplicação de calcário dolomítico (PRNT 90\%), 2,0 t/ha, e adubação de manutenção conforme recomendações da Sociedade Brasileira de Ciência do Solo (2004). A semeadura do azevém foi realizada em 30 de maio de 2005. Trinta dias após o plantio e na sequência de cada pastejo, realizou-se a adubação de cobertura com nitrogênio na forma de ureia (50 kg/ha).

Foram avaliadas duas oferta de forragem - baixa (25 kg MS/vaca.dia) e alta (40 kg MS/vaca.dia) - pelo método de lotação rotacionada com cinco dias de ocupação. O delineamento experimental foi o de dupla reversão com três períodos de 15 dias (dez de adaptação e cinco de coleta de dados). Nos intervalos dos períodos, todos os animais foram mantidos em pastagem de azevém sem qualquer suplementação energética ou proteica, numa oferta de forragem média de $30 \mathrm{~kg} \mathrm{MS/vaca.dia.} \mathrm{Os} \mathrm{animais} \mathrm{utilizados}$ foram dez vacas da raça Holandesa, divididas em dois grupos uniformes quanto à ordem de parição (primíparas ou multíparas), ao estádio de lactação ( $129 \pm 42$ dias), à produção de leite $(27,3 \pm 3,56 \mathrm{~kg} /$ dia) e ao peso (532 $\pm 56,5 \mathrm{~kg})$ no início do experimento. Sal mineral e água foram fornecidos à vontade durante todo o período experimental.

A área de pasto foi ajustada a cada cinco dias de acordo com a biomassa existente. O controle da biomassa foi feito utilizando-se um fio de cerca elétrica colocado à frente dos animais e um fio colocado atrás. A biomassa foi quantificada pela relação entre a altura - medida com um disco herbométrico (Filip's folding plate pasture meter ${ }^{\circledR}$, Jenquip CO., New Zealand) - e a quantidade de matéria seca presente na área relativa ao diâmetro do disco $\left(0,1 \mathrm{~m}^{2}\right)$. Cinco locais, abrangendo desde as áreas mais baixas até as áreas mais altas da pastagem, foram medidos e, em cada um, a totalidade da matéria seca existente no interior da área do diâmetro do disco foi cortada no nível do solo e seca em estufa com ventilação forçada a $60^{\circ} \mathrm{C}$ por 48 horas. Equações de regressão foram geradas para estimativa da biomassa presente (kg MS/ha) em cada altura herbométrica (cm). A média da altura herbométrica de cada piquete foi calculada utilizando-se no mínimo 100 leituras. A altura média de perfilho estendido e da bainha foi medida com uma régua graduada em 200 unidades por piquete, antes do pastejo, e em 300 unidades após o pastejo. A altura média ao primeiro toque na pastagem foi medida com um bastão graduado (sward stick), também a partir de 200 medidas por piquete antes do pastejo e em 300 medidas após o pastejo. A composição morfológica foi determinada por separação manual das frações folha, colmo e material morto das plantas de azevém-anual.

Antes do pastejo, em todos os períodos de avaliação, foram coletadas 20 amostras do pasto, com diâmetro de aproximadamente $10 \mathrm{~cm}$, cortadas com tesoura no nível do solo. Uma subamostra foi utilizada para determinação da composição morfológica e outra subamostra foi destinada a análises químico-bromatológicas. Essa subamostra foi congelada mantendo sua estrutura vertical e, para a realização das análises, foi cortada à altura média dos perfilhos após o pastejo. A fração superior foi seca em estufa com circulação de ar forçado a $60^{\circ} \mathrm{C}$ por 48 horas e armazenada para determinação dos teores de matéria seca (MS), matéria mineral (MM), proteína bruta (PB), fibra em detergente neutro (FDN) e fibra em detergente ácido (FDA).

O consumo individual de forragem foi medido pela quantificação da produção fecal e da digestibilidade da forragem ingerida. A produção fecal foi estimada utilizando-se um indicador externo (óxido de cromo, $\mathrm{Cr}_{2} \mathrm{O}_{3}$ ), fornecido diariamente para cada vaca por meio de $200 \mathrm{~g}$ de um concentrado peletizado contendo $0,5 \%$ de $\mathrm{Cr}_{2} \mathrm{O}_{3}$, do primeiro ao penúltimo dia de cada período experimental, depois de cada ordenha. Amostras de fezes 
foram coletadas duas vezes por dia, diretamente do reto dos animais, durante os últimos cinco dias de cada período experimental. As fezes foram secas em estufa com circulação de ar forçado a $60^{\circ} \mathrm{C}$ por 72 horas. No final do experimento, essas amostras foram agrupadas por vaca e por período, moídas em peneira de $1,0 \mathrm{~mm}$ e armazenadas para determinação dos teores de matéria seca, matéria mineral, proteína bruta, fibra em detergente neutro, fibra em detergente ácido e cromo.

A digestibilidade da matéria orgânica da forragem ingerida foi estimada por meio de indicadores de índice fecal, considerando o teor de proteína bruta na forragem e nas fezes e o teor de FDA nas fezes, de acordo com a equação descrita abaixo.

$\mathrm{DMO}=1,035-2,478 / \mathrm{PB}_{\text {fezes }}-0,00027 \mathrm{FDA}_{\text {fezes }}-$ $0,0571 \mathrm{~PB}_{\text {forragem }} / \mathrm{PB}_{\text {fezes }}$

$\left(\mathrm{n}=31, \mathrm{R}^{2}=0,92\right.$, erro-padrão $\left.=0,0094\right)$.

Essa equação foi obtida a partir dos resultados de 31 experimentos in vivo, conduzidos na fazenda experimental do Institut National de la Recherche Agronomique (INRA), próximo a Rennes (Bretanha, França). Nesses ensaios, foram utilizadas 3 a 4 vacas alimentadas em estábulos com forragem fresca de azevém-perene, Dactylis glomerata ou trevo-branco.

A produção de leite individual foi medida diariamente em cada ordenha. Amostras para determinação dos teores de gordura e proteína do leite foram coletadas em cada uma das ordenhas realizadas nos cinco dias de avaliação de todos os períodos experimentais. Uma vez por semana os animais foram pesados. O balanço energético foi calculado pela diferença entre o consumo de energia líquida (consumo de forragem $\times$ conteúdo de energia líquida da forragem) e as exigências em energia líquida para mantença e produção de leite. O conteúdo de energia líquida de lactação da forragem foi calculado considerando eficiência de utilização da energia metabolizável de 0,63 (INRA, 1989). A energia metabolizável da forragem ingerida foi estimada a partir da sua DMO (AFRC, 1993). As exigências em energia líquida foram calculadas de acordo com o sistema de unidade alimentar (UF) desenvolvido pelo INRA (1989).

A determinação da composição químico-bromatológica das amostras da forragem e das fezes foi realizada nas amostras secas ao ar e moídas em tamanho de 1,0 mm. A matéria seca total foi determinada por secagem a $105^{\circ} \mathrm{C}$ até peso constante. $\mathrm{O}$ teor de cinzas foi quantificado por incineração das amostras em forno mufla a $550^{\circ} \mathrm{C}$ por 4 horas. O teor proteína bruta $(\mathrm{N} \times 6,25)$ foi dosado por meio de um procedimento semimicro Kjeldahl (Silva \& Queiroz, 2002). As análises das frações FDN e FDA da forragem e das fezes foram realizadas considerando as cinzas residuais sem a utilização de $\alpha$-amilase (Robertson \& van Soest, 1981). A porcentagem de cromo foi quantificada por espectrofotometria de absorção atômica, após a digestão das cinzas (originadas de $1,0 \mathrm{~g}$ de amostra seca ao ar) em 6,0 mL. de uma solução ácida (250 mL de ácido sulfúrico, $250 \mathrm{~mL}$ de ácido ortofosfórico e $50 \mathrm{~mL}$ de solução sulfato de manganês $10 \%$ por litro de solução) e 3,0 mL de uma solução de bromato de potássio a 4,5\%.

Os dados foram submetidos à análise da variância utilizando um modelo linear generalizado (Statistical Analysis System - SAS, 1987), considerando nível de significância de 5\%. As variáveis dos animais foram analisadas considerando os fatores vaca, período e nível de oferta de forragem $(n=30)$. As variáveis da pastagem foram analisadas considerando os fatores período e nível de oferta $(n=6)$.

\section{Resultados e Discussão}

A biomassa e a altura da pastagem medida com disco herbométrico, bastão graduado ou por meio do comprimento dos perfilhos estendidos, antes da entrada dos animais, foram semelhantes $(\mathrm{P}>0,05)$ nas duas ofertas de forragem (Tabela 1). A altura das bainhas, contudo, foi aproximadamente $3,0 \mathrm{~cm}$ maior nos piquetes manejados com 40 kg MS/vaca.dia em relação àqueles manejados com $25 \mathrm{~kg}$ MS/vaca.dia.

A maior altura média de bainhas na maior oferta de forragem ocorreu provavelmente porque os piquetes utilizados no segundo e terceiro períodos foram os mesmos do primeiro período, com seus respectivos tratamentos experimentais. Dessa forma, o maior resíduo de colmos após o primeiro pastejo na mais alta oferta de forragem pode ter contribuído para a maior elongação de colmos nos períodos subsequentes. Maiores elongações de colmos em situação de menor eficiência de colheita da pastagem já foram observadas tanto em pastagens de azevém-perene submetidas a pastejo rotativo (Kristensen, 1988) como em pastagens de azevém-anual manejadas em lotação contínua (Pontes et al., 2004).

A composição química da forragem ingerida foi semelhante $(\mathrm{P}>0,05)$ nas duas ofertas de forragem (Tabela 1). Os teores de matéria seca, proteína bruta, fibra em detergente neutro e fibra em detergente ácido foram em média 15,5; 22,3; 53,0 e 24,3\%, respectivamente. Essa ausência de alteração na composição química de pastos manejados em diferentes ofertas de forragem foi observada também por outros autores (Stakelum, 1986; Stockdale, 1999). Neste trabalho, essa resposta pode ser parcialmente explicada pela menor altura inicial de bainhas observada em 
baixa oferta de forragem. Dessa forma, é possível concluir que as diferenças no consumo de forragem e na produção de leite observadas neste estudo não estão relacionadas ao valor nutritivo das pastagens, o que reforça o conceito de que, em pastagens de qualidade elevada (> 15\% de PB, aproximadamente 50,0\% de FDN), o desempenho animal é basicamente explicado pelo nível de ingestão, o qual é determinado sobretudo pela oferta de forragem e pela estrutura da pastagem (Delagarde et al., 2001a).

A oferta de matéria seca total observada, bem como as ofertas de matéria seca verde e matéria seca de lâminas, foi significativamente maior $(\mathrm{P}<0,01)$ na oferta de forragem mais alta (Tabela 2), situando-se em valores bastante próximos das ofertas de matéria seca pretendidas. As ofertas de matéria seca verde e de lâminas verdes foram, respectivamente, $12,0 \mathrm{~kg} / \mathrm{dia}$ e $3,2 \mathrm{~kg} /$ dia superiores $(\mathrm{P}<0,01)$ nas ofertas de forragem de 40 e $25 \mathrm{~kg}$ MS/vaca.dia. As alturas residuais medidas com disco herbométrico $(\mathrm{P}<0,10)$ e com bastão graduado $(\mathrm{P}<0,08)$ foram maiores na mais alta oferta de forragem. A altura residual dos perfilhos foi aproximadamente $10 \mathrm{~cm}$ superior $(\mathrm{P}<0,01)$ na mais alta oferta de forragem e a de bainhas em torno de $6,0 \mathrm{~cm}(\mathrm{P}<0,01)$ superior nos piquetes com alta oferta.

A altura residual de lâminas (altura residual de perfilhos - altura residual da bainha) foi de 5,4 $\mathrm{cm}$ na oferta de forragem de $40 \mathrm{~kg}$ MS/vaca.dia e de $1,9 \mathrm{~cm}$ na de $25 \mathrm{~kg}$ MS/vaca.dia Essa diferença pode explicar variações no consumo de forragem, uma vez que a altura residual de lâminas está associada ao consumo de forragem em situações de pastejo rotativo (Wade et al., 1995; Delagarde et al., 2001a). Segundo Wade et al. (1995), diminuições no consumo ocorrem a partir do momento em que a altura de lâminas atinge aproximadamente 5,0 cm. Essa diminuição foi quantificada por Delagarde et al. (2001a) em pastagens temperadas. De acordo com esses autores, a partir desse valor (5,0 cm), a redução na ingestão é de aproximadamente 1 kg MS/dia para cada centímetro de diminuição na altura residual de lâminas.

O consumo individual de matéria seca da forragem aumentou 4,7 kg/dia e o de matéria orgânica 4,4 kg/dia

Tabela 1 - Biomassa, altura e composição química em pastos de azevém-anual manejado em diversas ofertas de forragem

\begin{tabular}{|c|c|c|c|c|}
\hline & \multicolumn{2}{|c|}{ Oferta (kg MS/vaca.dia) } & \multirow[b]{2}{*}{ d.p.r. } & \multirow[b]{2}{*}{ Significância } \\
\hline & 25 & 40 & & \\
\hline Biomassa (kg MS/ha) & 2580 & 2638 & 315,0 & ns \\
\hline Disco herbométrico & 103,5 & 99,4 & 3,31 & ns \\
\hline Bastão graduado & 262,9 & 298,8 & 59,9 & ns \\
\hline Perfilho estendido & 341,8 & 391,6 & 21,66 & ns \\
\hline Matéria seca (\% forragem verde) & 14,6 & 16,5 & 0,64 & ns \\
\hline Matéria mineral & 9,7 & 8,35 & 1,21 & ns \\
\hline Proteína bruta & 22,5 & 22,1 & 1,71 & ns \\
\hline Fibra em detergente neutro & 53,0 & 53,0 & 2,54 & ns \\
\hline Fibra em detergente ácido & 24,7 & 23,9 & 1,32 & ns \\
\hline
\end{tabular}

ns $=$ não significativo; $*=\mathrm{P}<0,05 ; * *=\mathrm{P}<0,01 ; * * *=\mathrm{P}<0,001$

d.p.r. = desvio-padrão residual.

Tabela 2 - Altura pós-pastejo em pastos de azevém-anual manejados em duas ofertas de forragem

\begin{tabular}{|c|c|c|c|c|}
\hline & \multicolumn{2}{|c|}{ Oferta (kg MS/vaca.dia) } & \multirow[b]{2}{*}{ d.p.r. } & \multirow[b]{2}{*}{ Significância } \\
\hline & 25 & 40 & & \\
\hline Área oferecida (m²/vaca.dia) & 99,25 & 155,09 & 25,95 & ns \\
\hline MS total & 23,49 & 37,09 & 0,67 & $* *$ \\
\hline MS verde & 20,20 & 32,20 & 0,80 & $* *$ \\
\hline MS de lâminas foliares & 8,80 & 12,07 & 0,46 & $* *$ \\
\hline Bastão graduado & 66,4 & 125,7 & 0,70 & 0,08 \\
\hline Perfilho estendido & 78,8 & 176,1 & 8,28 & $* *$ \\
\hline Bainha estendida & 59,7 & 122,4 & 2,71 & $* *$ \\
\hline
\end{tabular}

ns = não-significativo; $* *=\mathrm{P}<0,01 ; * * *=\mathrm{P}<0,001$

d.p.r. = desvio-padrão residual. 
$(\mathrm{P}<0,001)$ quando a oferta de matéria seca total aumentou de 23,5 para 37,0 kg/dia (Tabela 3). A digestibilidade da matéria orgânica da forragem ingerida $(\mathrm{P}<0,05)$ e o balanço energético $(\mathrm{P}<0,001)$ durante os períodos de avaliação de consumo de forragem foram maiores nos animais mantidos nos pastos com maior oferta de forragem. Contudo, o peso vivo médio ao longo do experimento foi praticamente idêntico ao peso vivo inicial em ambos os lotes.

O aumento no consumo de forragem foi de $0,30 \mathrm{~kg}$ de matéria orgânica por kg de matéria seca oferecida a mais, valor praticamente idêntico ao observado por Peyraud et al. (1996) quando consideraram oferta de forragem superior a 4,0 cm do solo, mas um pouco acima do observado por outros autores quando a oferta de forragem foi calculada no nível do solo (Ribeiro Filho et al., 2005; Delagarde et al., 2001a; Wales et al., 1999; Wales et al., 1998; Peyraud et al., 1996). Da mesma forma, um modelo de predição do consumo de forragem para vacas leiteiras em pastejo, recentemente publicado (Delagarde \& O’Donovan, 2005), estima que, em faixa de variação na oferta semelhante à utilizada neste experimento, o aumento no consumo é de aproximadamente 0,2 kg MS/kg de MS oferecida.

A oferta de matéria seca total, no entanto, tem menor correlação com o consumo que a oferta de matéria seca de folhas (Delagarde et al., 2001b). Neste trabalho, as ofertas de MS de folhas foram 12,1 e 8,8 kg MS/dia nas ofertas de forragem alta e baixa, respectivamente. Segundo Parga et al. (2000), o consumo de forragem não é afetado por oferta de folhas verdes em torno de $13 \mathrm{~kg}$ MS/vaca.dia. Assim, os valores observados indicam que os animais na alta oferta de forragem praticamente não foram submetidos a limitações de ordem não-nutricional ao consumo (Poppi et al., 1987), o que certamente ocorreu nos animais submetidos à baixa oferta.

Do ponto de vista prático, a oferta de matéria seca de lâminas é uma variável difícil de ser medida. Contudo, em situação de pastejo rotativo, a intensidade de desfolha pode ser descrita de maneira simplificada pela relação entre as alturas médias de entrada e de saída (Virkajarvi et al., 2002; Delagarde et al., 2001b; Combellas \& Hodgson, 1979). Neste trabalho, a altura pré-pastejo foi a mesma em ambas as ofertas de forragem, mas a altura pós-pastejo, medida com disco herbométrico, foi menor $(\mathrm{P}<0,10)$ na mais baixa oferta de forragem. Essa variação impôs porcentagens de desaparecimento de forragem equivalentes a $69,0 \%$ na oferta de forragem baixa e a $49,0 \%$ na oferta de forragem alta. Considerando que proporções de desaparecimento superiores a 50\% da altura inicial provocariam diminuições no consumo de forragem (Delagarde et al., 2001b; Combelas \& Hodgson, 1979), o maior nível de oferta utilizado foi suficiente para não impor limitações ao consumo de forragem. Ao contrário, o baixo nível de oferta esteve sujeito às limitações impostas pela necessidade dos animais de pastejar os estratos inferiores do dossel, onde a massa do bocado e a velocidade de ingestão diminuem de acordo com a altura da pastagem (Barrett et al., 2001, McGilloway et al., 1999, Barthram, 1981).

Indicadores da pastagem, como a altura residual de lâminas, a oferta de matéria seca de lâminas verdes e a proporção de forragem desaparecida em relação à altura inicial, sugerem que o azevém-anual manejado em oferta de 37 kg de MS/vaca.dia não impõe restrições de ordem não nutricional ao consumo. Esse resultado está de acordo com as respostas curvilineares descritas por Peyraud et al. (1996) e Delagarde et al. (2001a), considerando outras espécies de clima temperado, e evidencia que a elevação do consumo de forragem depende de diminuição da eficiência de utilização da pastagem. Contudo, alguns autores afirmam que é possível aumentar a utilização da pastagem sem penalizar o consumo de forragem mediante a antecipação do primeiro pastejo (Kennedy et al., 2005) e de maiores intensidades (Parga et al., 2000) e/ou frequências de

Tabela 3 - Produção fecal, digestibilidade da forragem ingerida, consumo, peso vivo e balanço energético de vacas leiteiras em pastos de azevém-anual manejados com duas ofertas de forragem

\begin{tabular}{|c|c|c|c|c|}
\hline & \multicolumn{2}{|c|}{ Oferta (kg MS/vaca.dia) } & \multirow[b]{2}{*}{ d.p.r. } & \multirow[b]{2}{*}{ Significância } \\
\hline & 25 & 40 & & \\
\hline Produção fecal (kg MO/dia) & 2,78 & 3,82 & 0,437 & $* * *$ \\
\hline Digestibilidade $\mathrm{MO}$ forragem $^{1}$ & 0,74 & 0,75 & 0,008 & $*$ \\
\hline \multicolumn{5}{|l|}{ Consumo (kg/dia) } \\
\hline MS forragem & 11,9 & 16,6 & 1,81 & $* * *$ \\
\hline MO forragem & 10,8 & 15,2 & 1,65 & $* * *$ \\
\hline Peso vivo (kg) & 530,1 & 528,6 & 4,43 & ns \\
\hline Balanço energético (MJ EL lactação/dia)² & 3,5 & 31,4 & 15,16 & $* *$ \\
\hline
\end{tabular}

$*=\mathrm{P}<0,05 ; * *=\mathrm{P}<0,01 ; * * *=\mathrm{P}<0,001$.

d.p.r. = desvio-padrão residual.

1 Estimada a partir de indicadores de índice fecal.

${ }^{2}$ Calculado a partir de equações INRA (1989) e ARFC (1993). 
desfolha (Kristensen, 1988) no início da estação de crescimento das pastagens. Alternativas nesse sentido devem ser investigadas em pastos de azevém-anual.

A produção de leite $(\mathrm{P}<0,001)$, a produção de leite corrigida para $4 \%$ de gordura $\left(\mathrm{PL}_{4}\right)(\mathrm{P}<0,001)$, a produção de gordura $(\mathrm{P}<0,05)$ e a produção de proteína do leite $(\mathrm{P}<0,001)$ foram significativamente superiores nos animais submetidos à alta oferta de forragem (Tabela 4). A produção de leite e a $\mathrm{PL}_{4}$ aumentaram, respectivamente, $2,7 \mathrm{~kg} / \mathrm{dia}$ e 2,3 kg/dia quando aos animais passaram do pasto com baixa oferta de forragem para o pasto com alta oferta de forragem. Os teores de gordura e proteína do leite mantiveram-se inalterados com o nível de oferta de forragem apresentando valores médios de 33,5 e 28,6 g/kg, respectivamente.

O aumento na produção de leite com o acrésicmo na oferta de forragem foi de $0,2 \mathrm{~kg} / \mathrm{kg}$ de MS ofertada, um valor semelhante ao observado em outros estudos com plantas forrageiras de clima temperado (Peyraud et al., 1996). A produção de leite na mais alta oferta de forragem foi semelhante à observada em experimento com animais do mesmo rebanho em pastagem de azevém-anual com oferta de forragem semelhante, mas recebendo grão de milho como suplementação energética (Ribeiro Filho et al., 2007).

Do mesmo modo que a produção de leite, os teores de gordura e proteína foram próximos aos observados com o fornecimento de suplementação energética (Ribeiro Filho et al., 2007). Igualmente ao verificado por Ribeiro Filho et al. (2007), o teor médio de proteína manteve-se um pouco acima dos padrões mínimos de composição exigidos pela legislação vigente.

O balanço energético positivo é coerente com a inexistência de perda de peso vivo dos animais desde o início até o final do experimento (Tabela 3). Considerando que, mesmo nos intervalos entre as avaliações, a dieta foi composta exclusivamente de forragem pastejada e suplementação mineral, esse resultado comprova viabilidade da alimentação de vacas leiteiras exclusivamente a pasto após o pico de lactação.

Tabela 4 - Produção e composição do leite de vacas leiteiras em pastos de azevém-anual manejados com duas ofertas de forragem

\begin{tabular}{|c|c|c|c|c|}
\hline & \multicolumn{2}{|c|}{ Oferta (kg MS/vaca.dia) } & \multirow[b]{2}{*}{ d.p.r. } & \multirow[b]{2}{*}{ Significância } \\
\hline & 25 & 40 & & \\
\hline Produção de leite (kg/dia) & 18,38 & 21,09 & 1,72 & $* * *$ \\
\hline Teor de gordura $(\mathrm{g} / \mathrm{kg}$ ) & 33,9 & 33,1 & 0,14 & ns \\
\hline Teor de proteína (g/kg) & 28,3 & 29,0 & 1,0 & ns \\
\hline Produção de gordura (g/dia) & 631,2 & 709,9 & 75,44 & * \\
\hline
\end{tabular}

$*=\mathrm{P}<0,05 ; * *=\mathrm{P}<0,01 ; * * *=\mathrm{P}<0,001$.

d.p.r. = desvio-padrão residual.

1 Produção de leite $4 \%=\mathrm{PL} \times(0,4+0,15 \times$ teor de gordura/10).

\section{Conclusões}

Desde que manejado com alta oferta de forragem, o azevém-anual permite elevado consumo individual de matéria seca e produção de leite superior a $20 \mathrm{~kg} / \mathrm{dia}$, sem prejudicar o peso de vacas leiteiras no terço médio de lactação. Para cada kg de matéria seca de forragem oferecida a mais, a produção de leite aumenta $0,2 \mathrm{~kg} /$ vaca.dia. $\mathrm{O}$ aumento na produção é de $0,8 \mathrm{~kg}$ de leite por kg de matéria orgânica digestível ingerida. Quando manejado pelo método rotacionado, uma porcentagem de utilização de até 50\% da altura inicial pode ser utilizada como critério de manejo para evitar reduções na oferta que impliquem diminuição do consumo de forragem. Estudos futuros devem ser realizados para descrever as possíveis interações entre a oferta de forragem e a estrutura da pastagem com o objetivo de propor alternativas de manejo que possibilitem melhorar a produção animal sem penalizar excessivamente a utilização da pastagem.

\section{Literatura Citada}

AGRICULTURAL AND FOOD RESEARCH COUNCIL - AFRC. Energy and protein of requirements ruminants. Wallingford: CAB International, 1993. 159p.

AGUiNAGA, A.A.Q.; CARVALHO, P.C.D.; ANGHINONI, I. et al. Produção de novilhos superprecoces em pastagem de aveia e azevém submetida a diferentes altura de manejo. Revista Brasileira de Zootecnia, v.35, p.1765-1773, 2006.

BANDINELLI, D.G.; DE QUADROS, F.L.F.; MAXINER, A.R. et al, Desempenho animal em pasto de aveia e azevém com distintas biomassas de lâminas foliares. Pesquisa Agropecuaria Brasileira, v.40, p.1231-1238, 2005.

BARRETT, P.D.; LAIDLAW, A.S.; MAYNE, C.S. et al. Pattern of herbage intake rate and bite dimensions of rotationally grazed dairy cows as sward height declines. Grass and Forage Science, v.56, p.362-373, 2001 
BARTHRAM, G.T. Sward structure and the depth of the grazed horizon. Grass and Forage Science, v.36, p.130-131, 1981.

COMBELLAS, J.; HODGSON, J. Herbage intake and milk production by grazing dairy cows. I. The effects of variation in herbage mass and daily herbage allowance in a short-term trial. Grass and Forage Science, v.34 p.209-214, 1979.

DE FREITAS, F.K.; DA ROCHA, M.G.; RESTLE, J. et al. Suplementação energética na recria de fêmeas de corte em pastagem cultivada de inverno. Revista Brasileira de Zootecnia, v.34, p.1256-1266, 2005.

DELABY, L.; PEYRAUD, J.L.; DELAGARDE, R. Effect of the level of concentrate supplementation, herbage allowance and milk yield at turn-out on the performance of dairy cows in mid lactation at grazing. Animal Science, v.73, p.171-181, 2001.

DELAGARDE, R.; O'DONOVAN, M. Modelling of herbage intake and milk production by grazing dairy cows. In: MURPHY, J.J. (Ed.) Utilisation of grazed grass in temperate animal systems. Wageningen: Wageningen Academic Publishers, 2005. p.89-104.

DELAGARDE, R.; PEYRAUD, J.L.; DELABY, L. et al. Vertical distribution of biomass, chemical composition and pepsincellulase digestibility in a perennial ryegrass sward: interaction with month of year, regrowth age and time of day. Animal Feed Science and Technology, v.84, p.49-68, 2000.

DELAGARDE, R.; PRACHE, S.; D’HOUR, P. et al. Ingestion de l'herbe par les ruminants au pâturage. Fourrages, v.166, p.189-212, 2001a.

DELAGARDE, R.; PEYRAUD, J.L.; PARGA, J. et al. Caractéristiques de la prairie avant et après un pâturage: quels indicateurs de l'ingestion chez la vache laitière? Rencontres Recherches Ruminants, v.8, p.209-212, 2001b.

DIFANTE, G.D.; MARCHEZAN, E.; VILLA, S.C.C. et al. Produção de novilhos de corte com suplementação em pastagem de azevém submetida a doses de nitrogênio. Revista Brasileira de Zootecnia, v.35, p.1107-1113, 2006.

FARINATTI, L.H.E.; DA ROCHA, M.G.; POLI, C.H.E.C. et al. Desempenho de ovinos recebendo suplementos ou mantidos exclusivamente em pastagem de azevém (Lolium multiflorum Lam.). Revista Brasileira de Zootecnia, v.35, p.527-534, 2006.

FRESCURA, R.B.M.; PIRES, C.C.; DA ROCHA, M.G. et al. Sistemas de alimentação na produção de cordeiros para abate aos $28 \mathrm{~kg}$. Revista Brasileira de Zootecnia, v.34, p.1267-1277, 2005.

INSTITUT NATIONAL DE LA RECHERCHE AGRONOMIQUE INRA. Ruminant nutrition: Recommended allowances and feed tables. London: John Libbey, 1989. 389p.

KENNEDY, E.; O’DONOVAN, M.; MURPHY, J.P. et al. The effect of spring grazing date and stocking rate on sward characteristics and dairy cow production during midlactation. Journal of Dairy Science, v.90, p.2038-2046, 2007.

KRISTENSEN, E.S. Influence of defoliation regime on herbage production and characteristics of intake by dairy cows as affected by grazing intensity. Grass and Forage Science, v.43, p.239-251, 1988.

MCGILLOWAY, D.A.; CUSHNAHAN, A.; LAIDLAW, A.S. et al. The relationship between level of sward height reduction in a rotationally grazed sward and short-term intake rates of dairy cows. Grass and Forage Science, v.54, p.116-126, 1999.

PARGA, J.; PEYRAUD, J.L.; DELAGARDE, R. Effect of sward structure and herbage allowance on herbage intake and digestion by strip-grazing dairy cows. In: ROOK, A.J.; PENNING, P.D. (Eds.)
Grazing management. Okehampton: British Grassland Society, 2000. p.61-66. (Occasional Symposium, 34).

PEYRAUD, J.L.; COMERÓN, E.A.; WADE, M.H. et al. The effect of daily herbage allowance, herbage mass and animal factors upon herbage intake by grazing dairy cows. Annales de Zootechnie, v.45, p.201-217, 1996.

PONTES, L.D.; CARVALHO, P.C.D.; NABINGER, C. et al. Fluxo de biomassa em pastagens de azevém anual (Lolium multiflorum Lam.) manejada em diferentes alturas. Revista Brasileira de Zootecnia, v.33, n.3, p.529-537, 2004.

POPPI, D.P.; HUGHES, T.P.; L'HUILLIER, P.J. Intake of pasture by grazing ruminants. In: NICOL, A.M. (Ed.) Feeding livestock on pasture. Hamilton: New Zealand Society of Animal Production, 1987. p.55-63. (Occasional Publication, 10).

RIBEIRO FILHO, H.M.N.; DELAGARDE, R.; PEYRAUD, J.L. Herbage intake and milk yield of dairy cows grazing perennial ryegrass swards or white clover/perennial ryegrass swards at low- and medium-herbage allowances. Animal Feed Science and Technology, v.119, p.13-27, 2005.

RIBEIRO FILHO, H.M.N.; SEMMELMANN, C.E.N.; HEYDT, M.S et al. Suplementação energética para vacas leiteiras pastejando azevém com alta oferta de forragem. Revista Brasileira de Zootecnia, v.36, p.2152-2158, 2007

ROBERTSON, J.B.; VAN SOEST, P.J. The detergent system of analysis. In: JAMES, W. P. T.; THEANDER, O. (Ed.) The analysis of dietary fibre in food. New York: Marcel Dekker, 1981. p.123-158.

SAIBRO, J.C.; SILVA, J.L.S. Integração sustentável do sistema arroz $\mathrm{x}$ pastagens utilizando misturas forrageiras de estação fria no litoral norte do Rio grande do Sul. In: ANAIS DO IV CICLO DE PALESTRAS EM PRODUÇÃO E MANEJO DE BOVINOS DE CORTE, 4., 1999, Canoas. Anais... Canoas: Editora da ULBRA, 1999. p.27-55.

SILVA, D.J.; QUEIROZ, A.C. Análise de alimentos: métodos químicos e biológicos. 3.ed. Viçosa, MG: Universidade Federal de Viçosa, 2002. 235p.

SOCIEDADE BRASILEIRA DE CIÊNCIA DO SOLO - SBCS. Manual de adubação e calagem para os estados do Rio Grande do Sul e Santa Catarina. 10.ed. Porto Alegre: SBCS Núcleo Regional Sul, 2004. 400p.

STATISTICAL ANALYSIS SYSTEMS - SAS. SAS User's guide: Statistics, Version 1987. Cary: SAS Institute, 1987. (CD-ROM).

VIRKAJARVI, P.; SAIRANEN, A.; NOUSIAINEN, J.I. et al. Effect of herbage allowance on pasture utilization, regrowth and milk yield of dairy cows in early, mid and late season. Animal Feed Science and Technology, v.97, p.23-40, 2002.

WADE, M.H.; PEYRAUD, J.L.; COMERÓN, E.A.; LEMAIRE, G. The dynamics of daily milk production and sward height under paddock grazing conditions. Annales de Zootechnie, v.44, p.127, 1995 (suppl.).

WALES, W.J.; DOYLE, P.T.; DELLOW, D.W. Dry matter intake and nutrient selection by lactating cows grazing irrigated pastures at different pasture allowances in summer and autumn. Australian Journal of Experimental Agriculture, v.38, p.451-460, 1998.

WALES, W.J.; DOYLE, P.T.; STOCKDALE, C.R. et al. Effects of variations in herbage mass, allowance, and level of supplement on nutrient intake and milk production of dairy cows in spring and summer. Australian Journal of Experimental Agriculture, v.39, p.119-130, 1999. 